\title{
Analisis Perbandingan Protokol Routing OSPF dan RIPv2 Berdasarkan Variasi Jumlah Router Pada Jaringan MPLS dan Tanpa MPLS Menggunakan Simulator GNS3
}

\author{
(Comparative Analysis of OSPF and RIPv2 Routing Protocols Based on Variations in \\ The Number of Routers on MPLS and Non-MPLS Networks Using GNS3 Simulator)
}

\author{
Dudy Supriadi, Andy Hidayat Jatmika, I Wayan Agus Arimbawa \\ Dept Informatics Engineering, Mataram University \\ Jl. Majapahit 62, Mataram, Lombok NTB, INDONESIA \\ Email: dudyti12@gmail.com,[andy, arimbawa]@unram.ac.id
}

\section{*Penulis korespondensi}

\begin{abstract}
In a wide scope of a network, it cannot be denied that the number of nodes on the network will increase. This will cause a decrease in the performance of the routing protocol used. So, it is necessary to do research to determine the performance of the routing protocols used. Multiprotocol Label Switching or commonly abbreviated as MPLS is one method that can be used in tuning networks to improve network performance further. This technology can be the best option in terms of low cost and easy to implement. So, MPLS is the best choice of technology that must be tested for its current scalability. The research was conducted by applying simulation and analysis methods using GNS3 simulators and Iperfv3.6 tools. The results obtained showed that there was an increase in performance on the OSPF and RIPv2 routing protocols with MPLS. The Bitrate Parameter increases by $36.40 \%$, jitter by $15.14 \%$, and Packet Loss by $12 \%$ for the RIPv2 protocol when implementing MPLS. On the other hand, OSPF using MPLS has increased the bitrate value by $36.86 \%$, the jitter value is $\mathbf{2 0 . 6 5 \%}$, and packet loss is $8 \%$.
\end{abstract}

Key words: computer network, analysis, dynamic routing, GNS3, MPLS,

\section{PENDAhULUAN}

Paket yang lewat di suatu jaringan akan melewati beberapa pilihan jalur yang ada, namun kemungkinan besar tidak semua jalur akan dilewati oleh sebuah paket yang akan dikirimkan ke perangkat tujuan. Proses pemilihan jalur ini disebut dengan routing. Routing dynamic yaitu teknik merutekan dua komputer atau lebih dengan memanfaatkan algoritma tertentu dalam menentukan jalur yang dilewati secara otomatis. Dalam pemanfaatannya routing dynamic bekerja lebih efisien dibandingkan routing static karena dapat meningkatkan kemungkinan kesalahan pada saat menginputkan alamat jaringan dalam routing tabel. Beberapa teknik untuk merutekan jalur dalam jaringan antara lain dengan menggunakan protokol OSPF (Open Shortest Path First) dan RIPv2. OSPF merupakan protokol routing dynamic berjenis link State dimana protokol ini konvergensinya cepat dan path terbaik dipilih dari cost terendah. Protokol berjenis link state dapat mengetahui kondisi network secara lebih akurat. Selain OSPF terdapat juga routing protokol RIPv2 (Routing Information Protocol) yang termasuk dalam kategori distance vector dimana protokol ini menentukan path berdasarkan jumlah hop untuk mencapai tujuan. Kelebihan yang ditawarkan protokol ini apabila kecepatan link sama maka RIPv2 dapat bekerja lebih baik dibandingkan OSPF.

Semakin meluasnya cakupan sebuah jaringan maka tidak dapat dipungkiri mengakibatkan jumlah node pada jaringan akan semakin bertambah. Hal ini tentunya akan mengakibatkan penurunan performa dari protokol routing yang digunakan. Sehingga perlu dilakukannya penelitian untuk mengetahui kinerja protokol routing yang digunakan yaitu OSPF dan RIPv2 apabila diberikan beban jumlah router yang berbeda. Multiprotocol Label Switching atau biasa disingkat MPLS yang digunakan untuk tunning sehingga performa jaringan meningkat. Teknologi ini dapat menjadi opsi terbaik melihat dari segi biaya yang murah serta mudah dalam implementasinya. Dibandingkan teknologi lainnya yang memiliki prinsip kerja yang sama seperti ATM dan Frame Relay yang membutuhkan biaya yang tinggi dalam pengaplikasiannya. Sehingga MPLS menjadi teknologi pilihan terbaik yang harus diuji skalabilitasnya saat ini.

Parameter Quality Of Service yang digunakan pada penelitian ini meliputi Bitrate, Jitter, dan Packet Loss yang diuji dengan membebani jaringan oleh paket UDP dengan ukuran bandwidth yang divariasikan. Selanjutnya digunakan tools Iperf untuk mengukur parameter Quality of Service dan Wireshark sebagai Network Analyzer. Dengan adanya penelitian ini diharapkan dapat memberikan hasil perbandingan pada penelitian yang telah dilakukan sebelumnya dan dapat menjadi bahan acuan 
bagi Network Administrator dalam mempertimbangkan protokol yang digunakan pada jaringan MPLS sesuai dengan kebutuhannya.

\section{TINJAUAN PUSTAKA}

Penelitian [1] yang terkait dengan penelitian dengan mensimulasikan skenario jaringan pada pengujian VoIP serta skenario simulasi menggunakan simulator GNS3. Dari hasil pengujian simulasi menghasilkan topologi jaringan full mesh dengan jumlah 6 router lebih baik dibandingkan dengan 4 dan 5 router.

Penelitian [2] dengan melakukan simulasi dimana dilakukan perbandingan penggunaan MPLS dan tanpa MPLS pada layanan Video Streaming. Hasil penelitian menunjukkan bahwa jaringan yang telah konfigurasi MPLS lebih baik dibandingkan tanpa menggunakan MPLS.

Penelitian [3] dengan melakukan perbandingan protokol routing OSPF tanpa MPLS dan dengan MPLS menggunakan mikrotik RB9512Ui-2Hnd dimana berdasarkan hasil pengujian didapatkan hasil bahwa throughput protokol OSPF MPLS lebih baik dibandingkan OSPF tanpa MPLS.

Penelitian [4] dengan melakukan perbandingan antara protokol routing EIGRP, OSPF dan RIPv2 pada simulator GNS3. Hasilnya, protokol routing OSPF lebih bagus dibandingkan EIGRP dan RIPv2.

Penelitian [5] dengan melakukan perbandingan antara protokol routing EIGRP dan OSPF berbasis MPLS. Penelitian dilakukan dengan metode simulasi dan analisis. Didapatkan hasil bahwa nilai QoS OSPF dengan MPLS lebih baik dibandingkan dengan EIGRP dengan MPLS.

Penelitian [6] dengan melakukan perbandingan pada protokol OSPF dengan MPLS dan tanpa MPLS. Penelitian dilakukan dengan menggunakan mikrotik. Didapatkan hasil dengan melakukan pengujian pada layanan video streaming adalah MPLS dapat memperkecil nilai delay yang dihasilkan.

Penelitian [7] dengan melakukan perbandingan antara protokol OSPF dan RIP dalam mengukur paramaeter Quality Of Service. Pengujian dilakukan dengan menggunakan Network Simulator. Hasil yang didapatkan bahwa nilai QoS OSPF lebih baik dibandingkan RIP.

Penelitian [8] dengan melakukan analisis terhadap Transfer Rate Multiprotocol Label Switching studi kasus pada PT.Bank Commonwealth. Penelitian dilakukan dengan Simulasi dan analisis menggunakan simulator Cisco Packet Tracer. Hasil QoS yang didapatkan menunjukkan bahwa MPLS dengan media wireline lebih baik dibandingkan media wireless.

Penelitian [9] dengan melakukan perbandingan antara protokol routing Stable-DSDV dengan DSDV standar dengan metode simulasi dan analisis. Simulasi jaringan menggunakan simulator NS2. Hasil yang didapatkan menunjukkan bahwa Stable-DSDV memberikan hasil QoS yang lebih baik dibandingkan DSDV standar.

\section{Metode Penelitian}

Dari penelitian yang akan dilaksanakan maka dapat dirancangan proses penelitian secara umum pada Gambar 1.



Gambar.1. Proses Penelitian

\section{A. Studi Literatur}

Mengumpulkan dan mempelajari literatur yang berkaitan dengan jaringan komputer, peralatan, perancangan jaringan dan penggunaan jaringan MPLS. Pada tahap ini juga dilakukan pengumpulan artikel penelitian sebelumnya yang telah dilakukan terkait dengan protokol routing OSPF dan RIPv2 maupun MPLS. Apabila bahan keseluruhan telah terpenuhi selanjutnya melakukan perancangan topologi jaringan yang akan digunakan.

\section{B. Membangun Topologi Jaringan}

Tujuan dari tahapan ini yaitu mendesain topologi yang akan digunakan dalam penelitian. Terdapat tiga variasi jumlah router yang digunakan yaitu 5,10, dan 15. Pada masing-masing topologi terdapat dua PC yang berfungsi sebagai client dan server.

\section{B.1. Topologi jaringan OSPF dan RIPv2 dengan jumlah 5} router

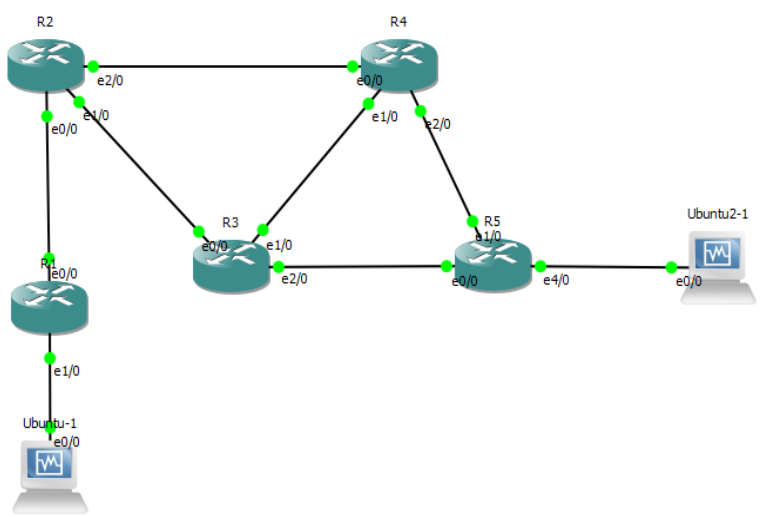

Gambar.2. Topologi jaringan OSPF dan RIPv2 dengan variasi 5 router 
Pada gambar 2 terdapat 5 node dengan topologi Mesh dimana masing-masing router akan dikonfigurasikan dengan protokol routing OSPF. Selanjutnya setelah konfigurasi pertama diuji akan digunakan konfigurasi protokol routing RIPv2. Pada tahap akhir dilanjutkan konfigurasi MPLS pada masing-masing node. Terdapat PC yaitu PC yang berfungsi sebagai client. Terdapat sebuah PC yang berfungsi sebagai Server.

\section{B.2. Topologi jaringan OSPF dan RIPv2 dengan jumlah} 10 router

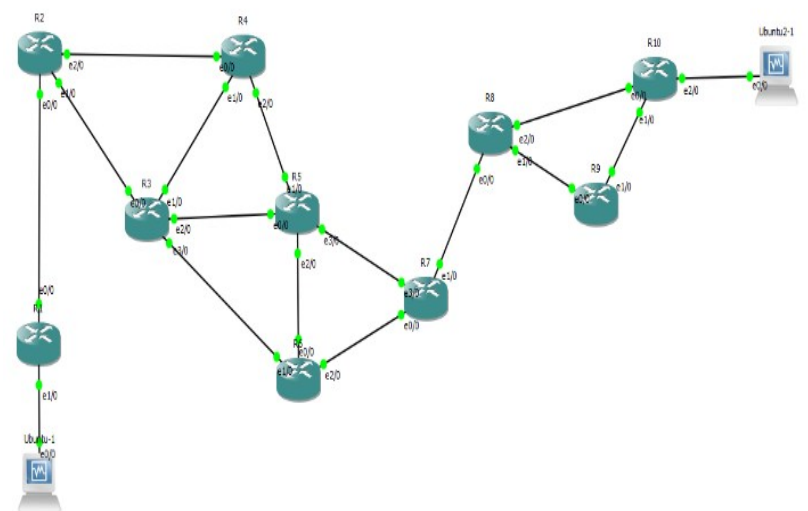

Gambar.3. Topologi jaringan OSPF dan RIPv2 dengan variasi 10 router

Gambar 3 menggambarkan 10 node dimana masingmasing router terhubung langsung pada topologi Mesh. Tahap awal akan dikonfigurasikan dengan protokol routing OSPF untuk memenuhi skenario pertama. Selanjutnya setelah konfigurasi diuji akan digunakan konfigurasi protokol routing RIPv2 pada skenario kedua. Selanjutnya mengkonfigurasikan MPLS pada masingmasing protokol. Terdapat PC sebagai client dan satu buah PC sebagai server.

\section{B.3. Topologi jaringan OSPF dan RIPv2 dengan jumlah 15 router}

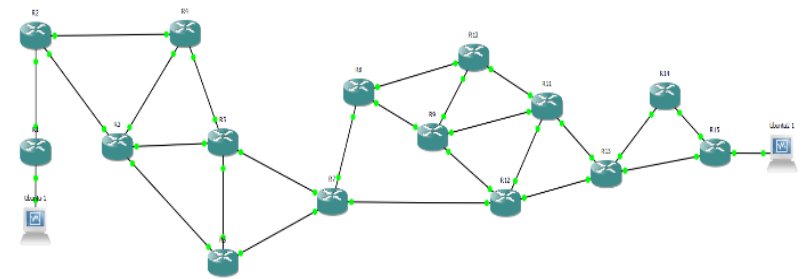

Gambar.4. Topologi jaringan OSPF dan RIPv2 dengan variasi 15 router

Pada gambar 4 terdapat 15 node dimana masing-masing router akan dikonfigurasikan dengan protokol routing OSPF. Selanjutnya setelah konfigurasi diuji akan digunakan konfigurasi protokol routing RIPv2.

\section{Instalasi OS dan Software.}

Pada tahap ini dilakukan instalasi software yaitu dengan menggunakan simulator GNS3. Selanjutnya melakukan instalasi VirtualBox sebagai perangkat lunak untuk membuat Operating System virtual dan router virtual dimana nantinya perangkat lunak ini akan diintegrasikan dengan simulator GNS3. Pada VirtualBox digunakan Operating System digunakan Linux Ubuntu LTS 14.0. Untuk mendukung proses pengujian digunakan tools Iperf.

\section{Instalasi Qemu Router.}

Pada tahapan ini akan dilakukan proses instalasi router Mikrotik CHR. Dalam hal ini Mikrotik berperan sebagai virtual router pada GNS3 yang diinstall pada Qemu. Mikrotik CHR digunakan karena perangkat ini dapat divirtualisasikan pada simulator dan lisensi bersifat gratis.

\section{E. Integrasi Perangkat Virtual.}

Mikrotik CHR yang telah diinstall selanjutnya akan diintegrasikan dengan GNS3 agar dapat digunakan pada simulator. Setelah Mikrotik CHR diintegrasikan selanjutnya melakukan integrasi sistem operasi yang digunakan yaitu Linux Ubuntu. Selanjutnya mengintegrasikan software yang digunakan untuk analisa yaitu wireshark.

\section{F. Konfigurasi Jaringan.}

Pada proses ini akan dilakukan konfigurasi protokol routing OSPF dan RIPv2 selanjutnya dilanjutkan dengan melakukan konfigurasi MPLS. Terdapat empat jenis konfigurasi yang berbeda pada masing-masing scenario diantaranya sebagai berikut.

\section{F.1. Konfigurasi OSPF Tanpa MPLS}

Pada tahap ini akan dilakukan konfigurasi terhadap protokol OSPF tanpa MPLS dengan konfigurasi sebagai berikut. Pada tahap awal melakukan konfigurasi ip address yang akan digunakan dengan syntax berikut ini.

/ip address add address=192.168.1.1
interface=ether 1

Penggunaan ip address selanjutnya disesuaikan dengan router beserta interface-nya. Setelah itu melakukan konfigurasi routing OSPF dengan syntx sebagai berikut.

/rout ospf instance set redistribute-
connected=as-type-1 router-id=1.1.1.1
/rout ospf network add area=backbone
network=192.168.1.0

Konfigurasi pertama mengatur instance pada mikrotik agar pengaturan berlaku pada semua interface OSPF. Perintah redistribute-connected=as-type-1 berfungsi sebagai pengaturan untuk menentukan area pada OSPF. Pada kasus ini area yang digunakan sama sehingga diatur dengan type 1. Pada perintah rout ospf network digunakan untuk menentukan alamat network interface ether1. Fungsi area=backbone berarti network berada pada area utama yaitu backbone area. Pada router yang lain berlaku proses konfigurasi yang sama dan disesuaikan dengan ip address yang digunakan. 


\section{F.2. Konfigurasi OSPF MPLS}

Pada tahap ini dilakukan konfigurasi OSPF dengan MPLS. Konfigurasi OSPF sama seperti konfigurasi sebelumnya namun terdapat penambahan syntax pada tahap akhir yaitu sebagai berikut.

/mpls ldp set enabled=yes transport-
address=9.9.9.1 lsr-id=9.9.9.1
/mpls ldp interface add interface=ether1
Pada konfigurasi ini dilakukan pengaturan untuk mengaktifkan fungsi MPLS pada mikrotik. Parameter transport address digunakan sebagai alamat distribusi label yang akan dilakukan pada saat pemindahan label MPLS. Selanjutnya mengaktifkan interface mpls agar MPLS dapat berjalan dengan baik.

\section{F.3. Konfigurasi RIPv2 Tanpa MPLS}

Pada tahap ini akan dilakukan konfigurasi terhadap RIPv2 dengan syntax sebagai berikut.

/rout rip int add int=ether1 senc=v2
receive=v2
/rout rip net add disabled=no
net=192.168.1.0

Pada konfigurasi ini dilakukan pengaturan interface pada protokol routing RIPv2. Selanjtunya melakukan pengaturan pada network address yang digunakan.

\section{F.4. Konfigurasi RIPv2 MPLS}

Pada tahap ini akan dilakukan pengaturan pada protokol routing RIPv2 MPLS dengan syntax sebagai berikut.

/rout rip set redistribute-connected=yes
/mpls ldp set enabled=yes transport-
address=9.9.9.1 lsr-id=9.9.9.1
/mpls ldp interface add interface=ether1

Pada konfigurasi ini diatur RIP agar dapat mendistribusikan label MPLS dengan perintah redistribute-connected=yes. Selanjutnya mengaktifkan fungsi MPLS seperti konfigurasi sebelumnya. Pada router yang lain berlaku mekanisme yang sama namun disesuaikan dengan ip address yang digunakan. Setelah tahap konfigurasi selesai harus dipastikan bahwa saat memeriksa routing table pada tiap router seluruh network sudah terdata dengan lengkap agar proses routing dapat berjalan dengan baik. Selanjutnya melakukan pengujian jaringan.

\section{G. Pengujian Jaringan.}

Dari Penelitian yang akan dilakukan maka dapat dirancang proses pengujian jaringan dengan membenani jaringan menggunakan paket UDP (User Datagram Protocol). Terdapat perbedaan mekanisme transmisi pada paket TCP (Transmission Control Protocol) dan UDP. Pada TCP terdapat acknowledgement diamana terdapat jaminan terhadapa paket yang gagal dikirimkan agar dapat dikirimkan kembali menuju ke tujuannya. Hal ini tentu berdampak pada penelitian ini dimana perlunya mengetahui parameter packet loss maupun jitter untuk mengetahui performa jaringan yang akan diuji. Jika pada penelitian ini dikirimkan paket TCP maka setiap paket yang gagal dikirimkan akan ditransmisikan ulang sehingga parameter packet loss tidak dapat terukur. Sebaliknya paket UDP bersifat unreliable artinya paket ini tidak akan mengirimkan ulang paket yang gagal diperjalanan. Sehingga parameter packet loss dan jitter yang dibutuhkan dalam penelitian ini dapat terukur dengan baik.

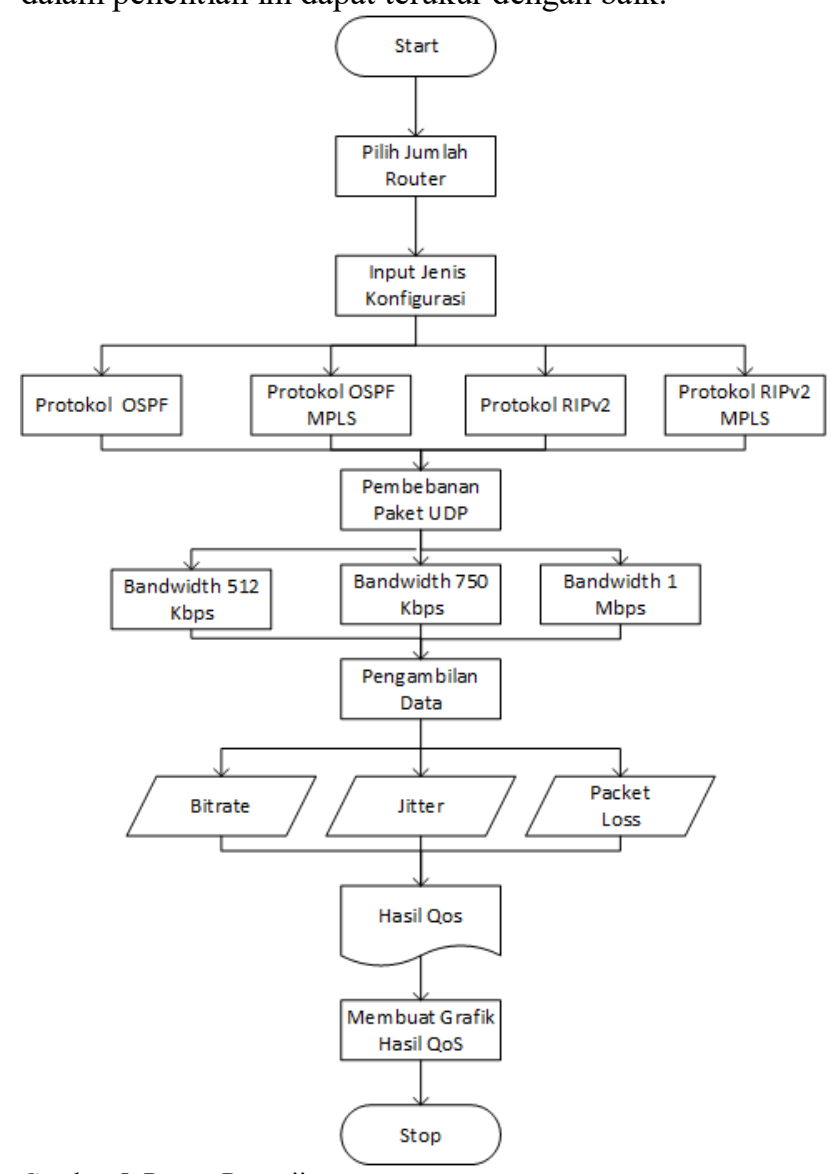

Gambar.5. Proses Pengujian

\section{G.1. Pilih Jumlah Router}

Proses simulasi ini terdapat tiga jenis topologi yang digunakan pada masing-masing protokol. Topologi pertama dengan jumlah router 5 selanjutnya 10 dan 15 . Pada scenario pertama digunakan variasi 5 router selanjutnya ditambahkan dengan 10 router hingga maksmimum dengan 15 router.

\section{G.2. Input Jenis Konfigurasi}

Jenis konfigurasi yang digunakan yaitu OSPF tanpa MPLS, RIPv2 tanpa MPLS, OSPF dengan menggunakan MPLS dan RIPv2 dengan menggunakan MPLS. Pada masing-masing skenario dilakukan pengujian dengan membebani jaringan dengan menggunakan paket UDP. Pengujian dilakukan dengan sepuluh kali perulangan dengan jeda waktu selama 5 menit.

\section{G.3. Pengujian Beban Paket UDP}

Pada pembebanan paket UDP ini dilakukan dengan membenani jaringan yang telah dikonfigurasi sebelumnya dengan paket UDP. Beban Variasi bandwidth yang digunakan yaitu 512 Kbps, 750 Kbps dan 1 Mbps. Pada 
penelitian ini digunakan Paket UDP karena paket ini tidak melakukan transmisi ulang apabila terjadi kegagalan paket saat dikirimkan sehingga paket ini dapat menghasilkan nilai packet loss dan jitter yang selanjutnya akan diukur dan dianalisa.

\section{G.4. Pengambilan data.}

Pada tahapan ini akan dilakukan pengambilan data terhadap parameter Quality of Service yang meliputi Bitrate, jitter dan packet loss. Pengambilan data dilakukan dengan melakukan perulangan sebanyak 10 kali tiap parameternya. Pada tahap pengambilan data dilakukan pengukuran dengan estimasi waktu pengamatan selama 10 detik pada tools Iperfv3.6.

\section{G.5. Hasil QoS}

Didapatkannya hasil rata-rata parameter QoS secara keseluruhan berdasarkan sample data yang dilakukan sebanyak 10 kali perulangan kemudian diambil nilai rataratanya. Terdapat tiga parameter QoS yang diambil diantaranya Bitrate, Jitter, dan Packet Loss. Setelah tahap ini selesai selanjutnya dilanjutkan dengan membuat grafik hasil QoS.

\section{G.6. Membuat grafik hasil QoS}

Hasil QoS yang telah dihitung kemudian akan disajikan dalam grafik berupa perbandingan hasil QoS pada dua jenis protokol routing. Kemudian dilakukan perbandingan terhadapa protokol OSPF dan RIPv2 baik menggunakan MPLS maupun tanpa MPLS.

\section{H. Kesimpulan.}

Pada tahapan ini akan ditarik kesimpulan berdasarkan hasil pengujian yang telah dilakukan.

\section{Hasil PENELITIAN DAN PEMBahasan}

\section{A. Hasil Perbandingan QoS OSPF MPLS dan Tanpa MPLS}

Berikut ini merupakan Tabel I perbandingan QoS OSPF Tanpa MPLS dan OSPF dengan menggunakan MPLS. Pada Tabel I dijelaskan bahwa terdapat tiga variasi bandwidth yang digunakan yaitu $512 \mathrm{Kbps}, 750 \mathrm{Kbps}$ dan 1 Mbps.

TABEL I PERBANDINGAN QOS OSPF TANPA MPLS DAN OSPF MPLS

\begin{tabular}{|l|c|c|c|c|c|c|c|c|c|c|}
\hline Bandwidth & \multicolumn{3}{|c|}{512 Kbps } & \multicolumn{3}{c|}{750 Kbps } & \multicolumn{3}{c|}{1 Mbps } \\
\hline Jumlah Router & 5 & 10 & 15 & 5 & 10 & 15 & 5 & 10 & 15 \\
\hline \multicolumn{10}{|c|}{ Bitrate (Kbps) } \\
\hline OSPF Tanpa MPLS & 373.2 & 213.3 & 135.8 & 304.7 & 160.6 & 76.49 & 297 & 142.82 & 77.95 \\
\hline OSPF MPLS & 420.4 & 225.5 & 169 & 612.2 & 230.1 & 97.61 & 741.8 & 162.2 & 103.2 \\
\hline \multicolumn{10}{|c|}{ Jitter (ms) } \\
\hline OSPF Tanpa MPLS & 36.68 & 48.8323 & 77.723 & 36.5024 & 51.7467 & 118.0803 & 38.8299 & 86.3194 & 120.0144 \\
\hline OSPF MPLS & 33.7212 & 43.4127 & 56.3512 & 19.7318 & 33.6467 & 60.7148 & 18.0231 & 35.75304 & 63.4736 \\
\hline \multicolumn{10}{|c|}{ Packet Loss (\%) } \\
\hline OSPF Tanpa MPLS & 19 & 51 & 63 & 53 & 73 & 87 & 63 & 82 & 90 \\
\hline OSPF MPLS & 11 & 44 & 61 & 15 & 63 & 82 & 20 & 80 & 87 \\
\hline
\end{tabular}

\section{A.1. Hasil Pengukuran Bitrate}

Berdasarkan Tabel I menggambarkan hasil dari pengukuran QoS antara OSPF tanpa MPLS dengan OSPF menggunakan MPLS yang kemudian diambil nilai rataratanya. Pengujian dilakukan dengan memvariasikan bandwidth sebesar 512 Kbps, 750 Kbps dan 1 Mbps. Hasil yang didapatkan berdasarkan dari pengujian yang telah dilakukan dimana OSPF dengan MPLS dapat meningkatkan performa dari protokol OSPF. Pada pengujian bitrate didapatkan hasil bahwa semakin bertambahnya jumlah router mengakibatkan penurunan nilai bitrate dimana hasil terbaik yang didapatkan pada OSPF MPLS dengan menggunakan 5 router sebesar 420.4 Kbps, 230.1 Kbps dan 741.8 Kbps. Apabila dibandingkan dengan hasil terbaik OSPF tanpa menggunakan MPLS pada penggunaan 5 router didapatkan hasil sebesar 373.2 Kbps, 304.7 Kbps, dan 297 Kbps.

\section{A.2. Hasil Pengukuran jitter}

Pada Tabel I digambarkan bahwa hasil pengukuran QoS untuk kategori jitter dimana semakin bertambahnya jumlah router yang digunakan maka berpengaruh terhadap peningkatan nilai jitter yang dihasilkan. Pengujian nilai jitter dilakukan dengan mensimulasikan jaringan yang telah dikonfigurasi baik menggunakan protokol routing OSPF dan RIPv2 pada jaringan MPLS maupun Tanpa MPLS menghasilkan selisih yang tidak begitu signifikan pada penggunaan bandwidth 512 Kbps. Namun pada penggunaan bandwidth yang lebih besar yaitu $750 \mathrm{Kbps}$ dan $1 \mathrm{Mbps}$, nilai jitter yang dihasilkan cukup memberikan selisih hasil yang signifikan. Nilai jitter terbaik dihasilkan pada OSPF menggunakan MPLS dengan menggunakan jumlah 5 router sebesar $33.7212 \mathrm{~ms}, 36.5024 \mathrm{~ms}$ dan 38.8299 ms pada penggunaan bandwidth $512 \mathrm{Kbps}, 750$ Kbps dan 1 Mbps.

\section{A.3. Hasil Pengukuran Packet Loss}

Beban bandwidth yang besar mengakibatkan jaringan menjadi sibuk sehingga dapat terjadinya overload pada jaringan. Berdasarkan pada Tabel I digambarkan bahwa semakin besar beban bandwidth, maka semakin besar nilai packet loss. Protokol routing OSPF dengan MPLS menghasilkan nilai packet loss yang lebih baik dibandingkan Tanpa menggunakan MPLS dimana nilai terbaik dihasilkan pada variasi 5 router sebesar $11 \%$ sedangkan OSPF Tanpa MPLS sebesar 19\%. Nilai Packet Loss terburuk dihasilkan oleh OSPF Tanpa MPLS dengan menggunakan bandwidth sebesar $1 \mathrm{Mbps}$ yaitu $90 \%$.

\section{B. Hasil Perbandingan QoS RIPv2 Tanpa MPLS dan RIPv2 MPLS}

Berikut ini merupakan Tabel II Perbandingan QoS RIPv2 Tanpa MPLS dan RIPv2 MPLS. Pada Tabel II dijelaskan bahwa terdapat tiga variasi bandwidth yang digunakan yaitu $512 \mathrm{Kbps}, 750 \mathrm{Kbps}$ dan $1 \mathrm{Mbps}$. Tabel II merepresentasikan kenaikan nilai Bitrate, jitter, dan Packet 
Loss. Terdapat juga variasi jumlah router yang digunakan yaitu 5,10 , dan 15 .

TABEL II PERBANDINGAN QOS RIPV2 TANPA MPLS DAN RIPV2 MPLS

\begin{tabular}{|l|c|c|c|c|c|c|c|c|c|c|}
\hline Bandwidth & \multicolumn{3}{|c|}{512 Kbps } & \multicolumn{3}{c|}{750 Kbps } & \multicolumn{3}{c|}{1 Mbps } \\
\hline Variasi Jumlah Router & 5 & 10 & 15 & 5 & 10 & 15 & 5 & 10 & 15 \\
\hline \multicolumn{10}{|c|}{ Bitrate (Kbps) } \\
\hline RIPv2 Tanpa MPLS & 346 & 202.6 & 129.51 & 347.1 & 222.7 & 148 & 403 & 217.9 & 141.06 \\
\hline RIPv2 MPLS & 403 & 222.5 & 150.19 & 629 & 246.6 & 179.9 & 767.3 & 243.9 & 166.7 \\
\hline \multicolumn{10}{|c|}{ Jitter (ms) } \\
\hline RIPv2 Tanpa MPLS & 46.8891 & 54.278 & 81.5886 & 34.5269 & 45.1983 & 64.5482 & 32.5874 & 47.8242 & 58.6355 \\
\hline RIPv2 MPLS & 34.6871 & 43.6931 & 67.0548 & 21.797 & 29.2221 & 42.7421 & 17.4398 & 31.7737 & 48.3321 \\
\hline \multicolumn{8}{|c|}{ Packet Loss (\%) } \\
\hline RIPv2 Tanpa MPLS & 24 & 53 & 67 & 49 & 64 & 76 & 53 & 74 & 83 \\
\hline RIPv2 MPLS & 15 & 47 & 62 & 12 & 60 & 71 & 20 & 72 & 79 \\
\hline
\end{tabular}

\section{B.1. Hasil Pengukuran Bitrate}

Pada perbandingan nilai bitrate yang ditunjukkan pada Tabel II yaitu Perbandingan QoS RIPv2 Tanpa MPLS dan RIPv2 MPLS dimana nilai bitrate RIPv2 menggunakan MPLS lebih baik dibandingkan Tanpa MPLS. Hasil pengukuran bitrate menunjukkan bahwa semakin bertambahnya jumlah router mengakibatkan penurunan nilai bitrate yang dihasilkan namun dengan memanfaatkan teknologi MPLS penurunan nilai yang buruk dapat diperbaiki meskipun tidak memberikan hasil yang begitu signifikan. Pada Penggunaan 5 router selisih hasil yang didapatkan memberikan nilai yang cukup signifikan yaitu RIPv2 Tanpa MPLS sebesar $403 \mathrm{Kbps}$ dan 767.3 Kbps. Namun seiring dengan bertambahnya jumlah terjadinya penurunan yang cukup signifikan baik pada RIPv2 MPLS maupun RIPv2 Tanpa MPLS. Pada RIPv2 MPLS digambarkan bahwa semakin bertambahnya jumlah router yang digunakan, selisih nilai yang dihasilkan tidak signifikan hal ini disebabkan oleh semakin banyaknya jumlah hop yang dilakukan maka performa dari MPLS semakin menurun. Sehingga dapat digambarkan bahwa semakin banyak jumlah hop, maka secara otomatis MPLS akan memanfaatkan bandwidth yang lebih besar.

\section{B.2. Hasil Pengukuran jitter}

Tabel II menggambarkan hasil perbandingan QoS RIPv2 MPLS dan Tanpa MPLS dimana berdasarkan hasil yang didapatkan menunjukkan bahwa RIPv2 MPLS lebih baik dibandingkan tanpa MPLS. Seiring dengan bertambahnya penggunaan jumlah router maka nilai jitter yang dihasilkan semaikin buruk. Pada RIPv2 MPLS didapatkan hasil terbaik pada penggunaan 5 router dengan nilai sebesar $17.4398 \mathrm{~ms}$ dibandingkan hasil yang terbaik yang didapatkan oleh RIPv2 tanpa MPLS sebesar 32.874 ms pada variasi bandwidth $1 \mathrm{Mbps}$. Berdasarkan hasil yang didapatkan nilai perbedaan yang diberikan pada protokol routing RIPv2 dengan MPLS maupun Tanpa MPLS memberikan selisih perbedaan yang tidak begitu signifikan. Pada hasil keduanya baik RIPv2 tanpa MPLS maupun
RIPv2 dengan MPLS memberikan hasil nilai jitter yang masih dibawah standar ITU-T sebesar 75 ms. Dengan demikian dapat disimpulkan bahwa MPLS dapat memperbaiki nilai jitter pada protokol routing RIPv2.

\section{B.3. Hasil Pengukuran Packet Loss}

Pada Tabel II Perbandingan QoS RIPv2 MPLS dan Tanpa MPLS menunjukkan bahwa semakin bertambahnya jumlah router pada protokol routing RIPv2 maka nilai packet loss yang diberikan akan semakin buruk. Namun dengan menggunakan MPLS penurunan performa dapat di minimalkan meskipun tidak memberikan selisih hasil yang signifikan. Berdasarkan nilai yang dihasilkan pada tabel 2 bahwa semakin besar beban bandwidth, maka makin besar nilai packet loss karena jumlah paket yang semakin besar akan berpengaruh terhadap antrian paket pada tiap-tiap router. Semakin banyak paket yang dibangkitkan maka jumlah antrian akan penuh dan secara otomatis akan mengakibatkan paket yang diluar antrian akan dibuang. Nilai packet loss terbaik yang diberikan pada RIPv2 tanpa MPLS yaitu pada variasi bandwidth $512 \mathrm{Kbps}$ sebesar $24 \%$ sedangkan pada RIPv2 MPLS sebesar $12 \%$ pada variasi bandwidth $750 \mathrm{Kbps}$.

\section{Hasil Perbandingan QoS OSPF dan RIPv2 Tanpa MPLS}

Berikut ini merupakan Tabel III perbandingan QoS OSPF dan RIPv2 Tanpa MPLS. Pada Tabel III dijelaskan bahwa terdapat tiga variasi bandwidth yang digunakan yaitu 512 Kbps, 750 Kbps dan 1 Mbps. Tabel III merepresentasikan kenaikan nilai bitrate, jitter, dan Packet Loss Seiring dengan bertambahnya jumlah router yang digunakan yaitu 5,10 , dan 15 .

TABEL III PERBANDINGAN QOS OSPF DAN RIPV2 TANPA MPLS

\begin{tabular}{|l|c|c|c|c|c|c|c|c|c|c|}
\hline Bandwidth & \multicolumn{3}{|c|}{512 Kbps } & \multicolumn{3}{|c|}{750 Kbps } & \multicolumn{3}{|c|}{1 Mbps } \\
\hline Variasi Jumlah Router & 5 & 10 & 15 & 5 & 10 & 15 & 5 & 10 & 15 \\
\hline \multicolumn{10}{|c|}{ Bitrate (Kbps) } \\
\hline OSPF Tanpa MPLS & 373.2 & 213.3 & 135.8 & 304.7 & 160.6 & 76.49 & 297 & 142.82 & 77.95 \\
\hline RIPv2 Tanpa MPLS & 346.2 & 202.6 & 129.51 & 347.1 & 222.7 & 148 & 403 & 217.9 & 141.06 \\
\hline \multicolumn{10}{|c|}{ Jitter (ms) } \\
\hline OSPF Tanpa MPLS & 38.68 & 48.8323 & 77.7723 & 36.5024 & 51.7567 & 128.0803 & 38.8299 & 85.3194 & 120.0144 \\
\hline RIPv2 Tanpa MPLS & 46.8891 & 54.278 & 81.5886 & 34.5269 & 45.1983 & 64.5482 & 32.5874 & 47.8242 & 58.6355 \\
\hline \multicolumn{10}{|c|}{ Packet Loss (\%) } \\
\hline OSPF Tanpa MPLS & 19 & 51 & 63 & 53 & 73 & 87 & 63 & 82 & 90 \\
\hline RIPv2 Tanpa MPLS & 24 & 53 & 67 & 49 & 64 & 76 & 53 & 74 & 83 \\
\hline
\end{tabular}

\section{C.1. Hasil Pengukuran Bitrate}

Tabel III merupakan hasil perbandingan QoS OSPF dan RIPv2 Tanpa MPLS dimana pada pengukuran bitrate RIPv2 lebih baik dibandingkan OSPF pada variasi bandwidth yang lebih besar yaitu $750 \mathrm{Kbps}$ dan 1 Mbps. Pada bandwidth yang menggunakan $750 \mathrm{Kbps}$ nilai bitrate RIPv2 lebih baik dibandingkan OSPF yaitu sebesar 347.1 Kbps dibandingkan OSPF hanya sebesar 304.7 Kbps. Sedangkan pada bandwidth 1 Mbps nilai bitrate yang dihasilkan RIPv2 sebesar 403 Kbps dan OSPF 297 Kbps. Nilai bitrate terbaik dihasilkan pada variasi jumlah yang 
menggunakan 5 router baik pada protokol routing OSPF maupun RIPv2. Sedangkan pada bandwidth $512 \mathrm{Kbps}$ nilai bitrate OSPF memiliki selisih yang tidak begitu signifikan dibandingkan RIPv2 yakni sebesar 373.2 Kbps dan 346.2 Kbps. Hal ini dipengaruhi oleh beban bandwidth yang diberikan dimana RIPv2 dapat bekerja lebih baik pada penggunaan bandwidth yang lebih besar yaitu $750 \mathrm{Kbps}$ dan 1 Mbps.

\section{C.2. Hasil Pengukuran Jitter}

Berdasarkan Tabel III yang menggambarkan hasil perbandingan QoS OSPF dan RIPv2 Tanpa MPLS dimana pengukuran nilai jitter memberikan hasil penurunan seiring dengan bertambahnya jumlah router yang digunakan baik MPLS maupun Tanpa MPLS. Nilai jitter terbaik pada perbandingan OSPF dan RIPv2 Tanpa MPLS diberikan pada variasi jumlah yang menggunakan 5 router dimana pada OSPF menghasilkan nilai sebesar $36.5024 \mathrm{~ms}$ dan RIPv2 sebesar $32.5874 \mathrm{~ms}$. Jitter yang makin besar akan mengakibatkan keterlambatan paket data berikutnya sehingga paket itu akan dibuang dan akan menyebabkan adanya packet loss.

\section{C.3. Hasil Pengukuran Packet Loss}

Berdasarkan pengukuran yang telah dilakukan digambarkan pada tabel III dimana semakin besar bandwidth yang diberikan maka packet loss yang dihasilkan pun semakin besar. Pada pengukuran bandwidth menggunakan $512 \mathrm{Kbps}$ nilai terbaik yang dihasilkan OSPF pada jumlah 5 router sebesar 19\% dan RIPv2 24\%. Selanjutnya pada bandwidth yang menggunakan $750 \mathrm{Kbps}$ nilai terbaik yang dihasilkan sebesar 53\% untuk OSPF dan RIPv2 sebesar 49\%. Sedangkan pada bandwidth 1 Mbps nilai packet loss OSPF sebesar 63\% dan RIPv2 sebesar $53 \%$. Hasil yang didapatkan menunjukkan bahwa pada bandwidth yang lebih besar yaitu $750 \mathrm{Kbps}$ dan 1 Mbps terjadi peningkatan performa pada protokol routing RIPv2. Hal ini terjadi karena protokol routing RIPv2 bekerja dengan memanfaatkan jumlah hop untuk nilai metric dalam proses routing guna menekan kongesti yang terjadi pada saat pengiriman paket dilakukan. Pada parameter Packet Loss dimana semakin besar bandwidth yang digunakan maka akan semakin banyak jumlah datagram yang dibangkitkan. Semakin banyak datagram yang dikirimkan akan mengakibatkan terjadinya kemacetan pada lalu lintas jaringan sehingga hal ini mengakibatkan semakin besarnya nilai packet Loss yang dihasilkan.

\section{Hasil Perbandingan QoS OSPF dan RIPv2 MPLS}

Hasil perbandingan QoS OSPF dan RIPv2 dengan menggunakan MPLS disajikan pada Tabel IV. Pada Tabel IV dijelaskan bahwa terdapat tiga variasi bandwidth yang digunakan yaitu $512 \mathrm{Kbps}, 750 \mathrm{Kbps}$ dan $1 \mathrm{Mbps}$. Tabel IV merepresentasikan kenaikan nilai bitrate, jitter, dan Packet Loss Seiring dengan bertambahnya jumlah router yang digunakan yaitu 5, 10, dan 15 .

\section{D.1. Hasil Pengukuran Bitrate}

Tabel IV merupakan perbandingan QoS OSPF dan RIPv2 MPLS. Pada bandwidth 512 Kbps nilai terbaik diberikan pada penggunaan 5 router sebesar 420.4 Kbps untuk OSPF MPLS dan 403.7 Kbps pada RIPv2 MPLS. Kemudian pada bandwidth $750 \mathrm{Kbps}$ nilai bitrate OSPF MPLS sebesar 612.2 Kbps dan RIPv2 MPLS sebesar 629.9 Kbps. Sedangkan pada penggunaan bandwidth 1 Mbps nilai bitrate untuk OSPF MPLS sebesar 741.8 Kbps dan RIPv2 767.3 Kbps. Berdasarkan tabel 4 digambarkan bahwa semakin bertambahnya jumlah router maka nilai bitrate yang dihasilkan semakin kecil. Nilai yang dihasilkan baik OSPF MPLS dan RIPv2 MPLS memberikan selisih hasil bitrate yang tidak signifikan

TABEL IV PERBANDINGAN QOS OSPF DAN RIPV2 MPLS

\begin{tabular}{|l|c|c|c|c|c|c|c|c|c|c|}
\hline Bandwidth & \multicolumn{3}{|c|}{512 Kbps } & \multicolumn{3}{|c|}{750 Kbps } & \multicolumn{3}{|c|}{1 Mbps } \\
\hline Variasi Jumlah Router & 5 & 10 & 15 & 5 & 10 & 15 & 5 & 10 & 15 \\
\hline \multicolumn{10}{|c|}{ Bitrate (Kbps) } \\
\hline OSPF MPLS & 420.4 & 222.5 & 169 & 612.2 & 230.1 & 97.61 & 741.8 & 162.2 & 103.2 \\
\hline RIPv2 MPLS & 403.7 & 222.5 & 150.19 & 629.9 & 246.6 & 179.9 & 767.3 & 243.9 & 166.7 \\
\hline \multicolumn{10}{|c|}{ Jitter (ms) } \\
\hline OSPF MPLS & 33.7212 & 43.4172 & 56.35 .12 & 22.7318 & 33.6467 & 60.7148 & 18.0231 & 35.75304 & 63.4736 \\
\hline RIPv2 MPLS & 34.6871 & 43.6931 & 67.0548 & 21.797 & 29.2221 & 42.7421 & 17.4398 & 31.7737 & 48.3321 \\
\hline \multicolumn{8}{|c|}{ Packet Loss (\%) } \\
\hline OSPF MPLS & 11 & 44 & 61 & 15 & 63 & 82 & 20 & 80 & 87 \\
\hline RIPv2 MPLS & 15 & 47 & 62 & 12 & 60 & 71 & 20 & 72 & 79 \\
\hline
\end{tabular}

\section{D.2. Hasil Pengukuran Jitter.}

Pada Tabel IV perbandingan QoS OSPF dan RIPv2 MPLS digambarkan bahwa nilai jitter yang didapatkan pada routing protokol baik RIPv2 maupun OSPF MPLS semakin bertambahnya jumlah router mengakibatkan peningkatan nilai jitter yang dihasilkan. Pada beban bandwidth yang menggunakan 1 Mbps didapatkan nilai terbaik pada penggunaan 5 router protokol routing RIPv2 MPLS sebesar 17.4398 ms sedangkan pada OSPF MPLS sebesar $18.0231 \mathrm{~ms}$. Pada variasi bandwidth $750 \mathrm{Kbps}$ dan 1 Mbps dengan menggunakan variasi jumlah 15 router terlihat selisih jitter yang cukup signifikan antara OSPF MPLS dan RIPv2 MPLS dimana RIPv2 MPLS lebih baik dibandingkan OSPF MPLS. Pada RIPv2 MPLS memberikan hasil sebesar $42.7421 \mathrm{~ms}$ dan $48.3321 \mathrm{~ms}$ sedangkan OSPF MPLS sebesar $60.7148 \mathrm{~ms}$ dan 63.4736 ms. Hal ini membuktikan bahwa RIPv2 MPLS mampu mempertahankan antrian packet secara teratur pada kondisi jumlah router yang lebih banyak.

\section{D.3. Hasil Pengukuran Packet Loss}

Berdasarkan Tabel IV Perbandingan QoS OSPF MPLS dan RIPv2 MPLS didapatkan bahwa semakin besar bandwidth, maka makin besar nilai packet loss-nya. Dibuktikan dengan hasil nilai terburuk dari RIPv2 MPLS maupun OSPF MPLS pada variasi 15 router. Packet Loss yang dihasilkan pada RIPv2 MPLS pada $512 \mathrm{Kbps}, 750$ Kbps dan 1 Mbps sebesar 61\%, 62\% dan 67\%. Sedangkan 
Pada OSPF MPLS sebesar $62 \%, 71 \%$ dan $79 \%$. Terjadinya packet loss dapat diakibatkan beberapa factor seperti terjadinya kongesti maupun overload pada antrian paket. Pada perbandingan OSPF dimana keduanya menggunakan teknologi MPLS didapatkan selisih hasil nilai packet loss yang tidak signifikan diantara keduanya.

\section{E. Grafik Perbandingan QoS OSPF dan RIPv2 dengan MPLS maupun Tanpa MPLS}

Adapun hasil dari pengukuran yang kemudian disajikan dalam bentuk grafik dengan parameter bitrate, jitter, dan Packet Loss akan dijabarkan sebagai berikut.



Gambar.6. Grafik Perbandingan Bitrate

Pada gambar 6 merupakan grafik perbandingan bitrate berdasarkan hasil pengukuran yang telah dilakukan dimana terdapat tiga variasi bandwidth yang digunakan antara lain 512 Kbps, 750 Kbps dan 1 Mbps. Pada penggunaan 5 router menghasilkan nilai bitrate yang cukup besar karena pada jumlah ini karena paket data masih dapat ditransmisikan dengan baik. Namun seiring dengan bertambahnya jumlah terjadi penurunan nilai yang cukup signifikan. Terlihat perbedaan yang cukup jelas pada variasi bandwidth $512 \mathrm{Kbps}$ dan $750 \mathrm{Kbps}$ dimana penurunan yang cukup signifikan pada jumlah 10 hingga 15 router. Hal ini dapat terjadi karena jarak dari sumber paket menuju tujuan semakin jauh atau dapat dikatakan jumlah hop yang dibutuhkan semakin banyak. Semakin jauh jarak yang harus dicapai dapat memungkinkan terjadinya kegagalan transmisi di perjalanan.

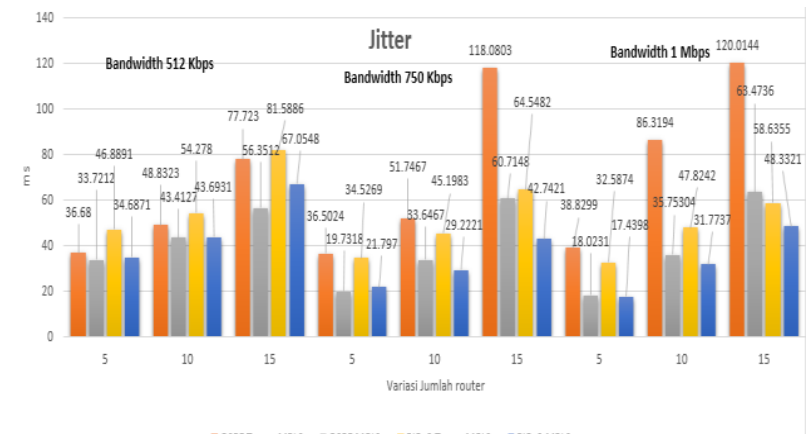

Gambar.7. Grafik Perbandingan Jitter

Gambar 7 merupakan grafik perbandingan jitter berdasarkan pengukuran yang telah dilakukan. Terdapat tiga variasi bandwidth yang digunakan antara lain 512 Kbps, 750 Kbps dan 1 Mbps. Pada pengukuran nilai jitter, semakin bertambahnya jumlah router mengakibatkan peningkatan nilai jitter yang dihasilkan. Hal ini terjadi diakibatkan semakin jauh jarak yang dituju dapat mempengaruhi antrian antar paket yang dikirimkan. Semakin jaruh jarak dari sumber ke tujuan dapat menyebabkan keterlambatan atau jeda yang terjadi antara paket satu dengan lainnya. Sehingga pada jumlah10 hingga 15 router terjadi peningkatan yang cukup signifikan pada parameter jitter.

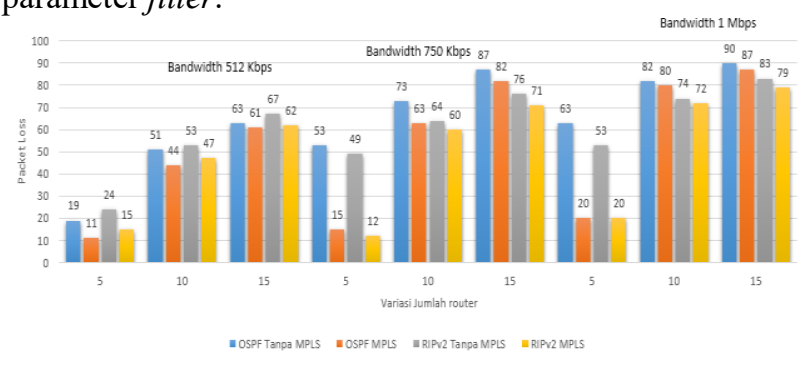

Gambar.8. Grafik Perbandingan Packet Loss

Pada gambar 8 merupakan grafik perbandingan packet Loss berdasarkan hasil pengukuran yang telah dilakukan. Terdapat tiga variasi bandwidth yagn digunakan antara lain 512 Kbps, 750 Kbps dan 1 Mbps. Berdasarkan grafik yang disajikan, nilai packet loss semakin meningkat seiring dengan besarnya bandwidth yang digunakan. Hal ini dapat terjadi karena semakin besar bandwidth yang digunakan maka jumlah datagram yang dikirimkan akan semakin bertambah banyak. Sehingga dapat mengakibatkan terjadi kongesti atau kemacetan antar paket yang dikirimkan. Semakin banyak kemacetan yang terjadi antar paket menghasilkan nilai packet loss yang semakin besar. Terlihat pada variasi bandwidth $750 \mathrm{Kbps}$ dan $1 \mathrm{Mbps}$ menghasilkan nilai packet loss yang lebih besar dibandingkan 512 Kbps.

\section{PENUTUP}

\section{A. Kesimpulan}

Berdasarkan hasil penelitian yang telah dilakukan maka dapat disimpulkan bahwa.

1) Pada protokol routing OSPF maupun RIPv2 menghasilkan nilai QoS yang buruk seiring dengan bertambahnya jumlah router yang digunakan. Berdasarkan standar ITU-T nilai QoS untuk parameter packet loss sebesar $25 \%$ sebagai kategori degradasi yang jelek. Sedangkan hasil pengukuran yang didapatkan nilai terburuk packet loss sebesar $90 \%$ pada protokol OSPF dan RIPv2 sebesar 83\%. Namun dengan memanfaatkan teknologi MPLS kualitas yang memburuk dapat diperbaiki sehingga menghasilkan QoS yang lebih baik meskipun tidak memberikan selisih hasil yang cukup signifikan. Pada Parameter Bitrate terjadi peningkatan sebesar $36.40 \%$, jitter sebesar 15.14\%, dan Packet Loss sebesar 12\% untuk protokol RIPv2 dengan diterapkannya MPLS. Sebaliknya OSPF dengan menggunakan MPLS terjadi peningkatan nilai bitrate sebesar $36.86 \%$, nilai jitter sebesar $20.65 \%$, dan packet loss sebesar $8 \%$. 
2) Pada penggunaan bandwidth sebesar $750 \mathrm{Kbps}$ dan 1 Mbps terjadi peningkatan performa dari protokol routing RIPv2 dimana protokol ini menghasilkan nilai QoS yang lebih baik dibandingkan OSPF. Pada bandwidth $750 \mathrm{Kbps}$, Nilai bitrate untuk RIPv2 menghasilkan nilai sebesar $347.1 \mathrm{Kbps}$, rata-rata jitter $34.5269 \mathrm{~ms}$, dan rata-rata packet loss sebesar 49\%. Sebaliknya OSPF menghasilkan nilai QoS yang lebih rendah dimana dihasilkan nilai bitrate sebesar 304.7 Kbps, rata-rata jitter sebesar $36.5024 \mathrm{~ms}$ dan rata-rata packet loss sebesar 53\%. Pada bandwidth 1 Mbps protokol routing RIPv2 menghasilkan bitrate sebesar $403 \mathrm{Kbps}$, rata-rata jitter $32.5874 \mathrm{~ms}$ dan packet loss sebesar 53\%. Sebaliknya OSPF menghasilkan nilai yang lebih rendah yaitu pada bitrate menghasilkan nilai sebesar 297 Kbps, rata-rata jitter 38.8299 ms, dan packet loss sebesar $63 \%$.

3) Semakin besar variasi bandwidth yang digunakan mengakibatkan beban jaringan semakin sibuk sehingga terjadi overload pada trafik jaringan dimana buffer atau antrian pada masing-masing router mengharuskan membuang paket yang berada diluar antrian. Selain itu, jaringan yang sibuk juga dapat menyebabkan terjadinya kongesti atau tumbukan pada saat paket dikirimkan dari sumber ke tujuan. Hal ini dibuktikan pada hasil pengukuran Pada protokol routing OSPF maupun RIPv2. Pada bandwidth 512 Kbps untuk protokol routing OSPF nilai packet loss terburuk dihasilkan sebesar 63\%. Penambahan bandwidth menjadi $750 \mathrm{Kbps}$ terjadi kenaikan nilai menjadi sebesar 87\% dan 1 Mbps menjadi sebesar 90\%. Sedangkan pada RIPv2 nilai packet loss pada bandwidth $512 \mathrm{Kbps}$ menghasilkan nilai terburuk sebesar $62 \%$. Pada bandwidth $750 \mathrm{Kbps}$ meningkat menjadi sebesar $76 \%$ dan 1 Mbps meningkat menjadi sebesar $83 \%$. Sehingga dapat disimpulkan bahwa nilai packet Loss semakin besar seiring dengan besarnya variasi bandwidth yang diberikan.

\section{B.Saran}

Adapun saran untuk penelitian selanjutnya adalah sebagai berikut.

1) Menggunakan protokol routing yang berbeda seperti RIPng dan OSPFv3.

2) Menggunakan IPv6.

3) Melakukan pengujian dengan menggunakan topologi yang berbeda.

4) Menggunakan perangkat mikrotik real.

5) Menggunakan pengujian yang berbeda seperti HTTP, FTP dan Video Streaming.

\section{DAFTAR PUSTAKA}

[1] D. B. Sumaryanto, "Simulasi Dan Analisis Variasi JumlahRouter BGP Pada Jaringan MPLS,” 2013.

[2] D. Y. Prawira, "Analisis Kinerja Jaringan Multiprotocol Label Switching untuk Layanan Video Streaming," vol. 13, 2015.

[3] B. Theo, "Analisis Peningkatan Unjuk Kerja Protokol Routing OSPF Dengan MPLS Menggunakan Mikrotik RB951Ui-2Hnd," 2015.

[4] L. Arung, "Analisis Perbandingan QoS Protocol EIGRP, OSPF, Dan RIPv2 Pada Link Antara Router Provider Edge (PE) dengan Router Customer Edge (CE) Pada Jaringan MPLS-VPN," vol. 1, 2012.

[5] Ma'ad, "Analisa Perbandingan QOS Pada Jaringan MPLS Berbasis Routing EIGRP dan OSPF," 2014.

[6] Z. Vonny, "Implementasi Teknologi MPLS Menggunakan Routing Protokol OSPF Pada Router Mikrotik," 2017.

[7] A. Setiawan, "Perbandingan Quality Of Service Routing Information Protocol Dengan Open Shorthest Path First," vol. 1, 2012

[8] M. Erliana, "Studi Analisa Transfer Rate Multiprotocol Label Switching Pada Media Akses Wireless Dan Wirelined PT.Bank Commonwealth (PTBC)," 2015.

[9] H. Akbar, "Analisis Pengaruh Metode LET Pada Protokol Routing Proaktif dan Reaktif Di Jaringan MANET," vol. 2, 2018.

[10] Sofana, I., "Jaringan Komputer Berbasis Mikrotik"., Informatika Bandung, Bandung, 2017.

[11] Nughroho, K., "IP Routing Menggunakan CISCO dan Mikrotik”., Informatika Bandung, Bandung, 2016. 